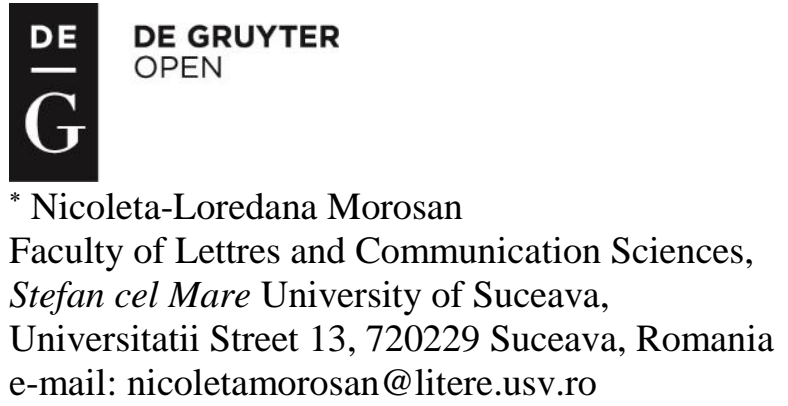

\title{
(IR)REVERENTLY TELLING THE OTHERNESS THROUGH PARATEXTUAL NARRATIVE
}

\begin{abstract}
An inherent component of relocation narratives is the description of the protagonists' process of building up their intercultural competence - whose range will vary from one expatriate narrator to another. Closely connected to all the four types of cultural intelligence (CQ), in general, and to the metacognitive CQ, in particular, the account of the sojourn in foreign lands conjures up a raft of reflections on what exactly gives one the sense of cultural belonging. Noticing the difference, analysing it, integrating or dismissing it are as many steps taken during/after cross-cultural interactions. This paper addresses the verbalisation of the cultural differences in accounts that sometimes embrace and other times reject them, by resorting to risqué language in snide remarks meant to perform an evaluation of the received ideas in relation to both the native and the host country of the expatriate. The corpus examined is the construction of the paratext prefiguring the spot-on satire comprised by the text.
\end{abstract}

Keywords: relocation narrative, cultural assumptions, derisive witticism, peritext, epitext

\section{Architextual Belonging of Stephen Clarke's A Year in the Merde}

At a time when, for a wide array of reasons, ranging from dire necessity to art de vivre, transnational mobility is a prevalent phenomenon characterising the dynamics of the world, travel writing can but accompany and foreground the experience of otherness. In this respect, the numerous accounts of lifestyle-motivated attempts made by Americans to gradually become an integral part of a French environment have given rise to a full-fledged genre, the literature of accommodation (Knox, 2003). According to the type of the French backdrop these narratives are set against, this literary category will embrace two directions. It will show Americans either living in provinces like the sunny Provence, in Southern France, "seeking out sensuous experience through food and climate" while aspiring to, if not virtually living an idyllic rural life as "a form of contact with a past soon to be, if not already, lost", or residing in Paris - in which case the writing will tap issues of "intellectual and artistic culture, as well as institutional practices" (Knox, 2003: 95). By extrapolation, this literary trend can encompass all the accounts made by lifestyle Anglophone migrants of their settlement (be it temporary or permanent) in a Francophone environment.

In reference to this type of literature (which very often is also concerned with sampling the lifestyle specific to Italian picturesque regions), L. A. Mastellotto speaks about relocation narratives as a "distinct subgenre of contemporary travel memoirs, concerned with the inter-subjective intrasubjective experiences of travellers who become settlers in foreign locale" (Mastellotto, 2005: 2). Actually, since dwelling on the process of settlement abroad, it is only accurate to say that these memoirs assume their consistency first and foremost by showcasing an experience of staying put and not of travelling per se (George \& Sattin, 2002, Ross, 2009, 2010). As cultural products stemming from

\footnotetext{
* Dr Nicoleta-Loredana Morosan is Assistant Professor of French Language. Her research interests include pluralistic approaches to languages and cultures: intercultural approaches, integrated didactic approaches, intercomprehension between related languages.
} 
one's need to acknowledge, to tell, at times to strongly counteract and reshape, whilst at other times to overtly integrate the distinctiveness between one's own culture and their culture of adoption, the relocation narratives ultimately focus on the process of scrutinising and remodelling identities. Preoccupied with addressing not only the encounter but also the gap between the expatriate's way of judging reality and the outlooks displayed by the foreign locals that the latter is surrounded by, the writing process can assume redeeming attributes as it may be contributing to the enterprise to make sense of the various differences in viewpoints.

Ultimately, this subgenre of travel writing produces proof of the degree of intercultural competence demonstrated both by the expatriate sojourning in foreign soils and by the locals with whom he engages interaction. One important component contributing to the enhancement of this competence is the cultural intelligence (CQ), understood as "an individual's capability to function effectively in situations characterised by cultural diversity" (Ang \& Van Dyne, 2008, Ang, Van Dyne \& Koh, 2006, Earley \& Ang, 2003). Based on the four-level model of intelligence identified by R. J. Sternberg (1986), P. C. Earley and S. Ang distinguished four complementary facets interwoven in the construct of cultural intelligence: metacognitive, cognitive, motivational and behavioural CQ. First and foremost, the relocation narratives stem from and are the substantiation of the metacognitive cultural intelligence, the individual's level of "conscious cultural awareness during cross-cultural interactions" (Earley \& Ang, 2003) -, that they take one step further, post the cross-cultural experience. Thus the subsequent narrative is the outcome of the reflection conducted (admittedly, to a greater or lesser extent) on the experience abroad by the expatriate writer.

\section{The Effrontery of the Title in Relation to the Cross-Cultural Experience}

One way of tackling the discrepancies between one's native and foreign cultural frames of reference is by humour and irony, whose forms will range from gentle banter and (self-)deprecation to caustic mockery aimed at sanctioning what seems to be completely irrational to the representative of the other culture. The work of the British journalist and writer Stephen Clarke who, once established in France, started drawing on his work experience within a French press group to tell the story of a FrancoBritish encounter is illustrative of this strain of travel writing. His first novel which stirred wide interest and enthusiasm, acquiring him large readership, is called A Year in the Merde. It was first published in 2004, after his ten years of Parisian residency, when the Anglo-French relationships were under strain, during the Iraq War of spring 2003. To be more accurate, it was self-published under the pen name Paul West - which is also the name of the main character in the book -, an English expatriate in the name of whom the first-person narrative starts unfolding before the reader's eyes.

Once put into the perspective of the cross-cultural cross-Channel experience, the surname of this character/narrator, West, pokes fun at the Englishman's French perceptions, for it may be read in the key of the French colloquial expression être complètement à l'ouest. Its French interpretation then becomes: "1. be spaced out; not be with it; 2 . dazed and confused; have one's head in the clouds" (Reverso Dictionary). Could it be that the British expat feels he is being subjected to an alienating experience in the foreign land? And if so, how will he cope with it? Will he balk in the face of difference? Will he willingly engage in intercultural exchanges, trying to make the best of them?

The following editions of the initial "fake autobiography" (Clarke), published by Bantam and Black Swan, reveal from the outset, namely their paratext, that the coping mechanisms (acid humour, voracious irony) are worked at their peak all along the cross-cultural awareness process. The first element of the auctorial peritext, the title, consists in an interlinguistic interaction between English and French: A Year in the Merde. Once the novel's architextual belonging (Genette, 1982) to the travel literature is known to the reader, the English part of the title is evocative of Peter Mayle's A Year in Provence (1989). (As a matter of fact, in the case of the reader of the Red Garage Books edition, brought out under the pseudonym Paul West, the intertextual reference to Mayle's work is blatantly obvious, as the subtitle unambiguously reads: "The Antidote to A Year in Provence".) Yet, the expectations raised by the intertextual analogy with the content of the overall sunny Provençal adventures narrated by Mayle are immediately undermined by the presence of what constitutes the French contribution to the title. If the French insertions in the English discourse usually enjoy high status and are commonly viewed as a sign of distinction and sophistication on the part of the addresser, in this instance, the insertion of the scatological word, often used as a swear word, merde, is far from emanating any sense 
of prestige, demoting the other language to a lowly rank. By way of consequence, the latter part of this peritextual element provides the reader with a dismal glimpse into what he is to read. Despite what might be called the commonality of the rude assertive speech act (Searle, 1975) accomplished by having recourse to this word in everyday life by many French people (a speech act that is accomplished in a similar manner in English as well as in a number of other languages), it nonetheless delivers a verdict. As an expressive speech act, the title is the conclusion to an almost one-year experience, from September to May, foretokening a narrative set on French bashing. The epitext surrounding the presence of this text into the world (Genette, 1982), an interview given by the author himself in 2011, elucidates the intertextual link, whilst distancing itself from the outlook displayed by its hypotext A Year in Provence:

There was a famous book with a similar title, about the "difficulties" of living in Provence. I was writing about the much less poetic problems of settling into a job in Paris, living in tiny apartments, battling with bureaucrats and mangling the French language, and tried to come up with a word that was the opposite of Provence. And it was merde.

The noun, understood through the prism of its connotations at the first reading of the title, takes back its denotative meaning, once the Table of contents is glanced through. Chapter 2 bears the title One foot in the merde. The subtitle, taking the form of a comment enlightening the reader with respect to the main topics that are to be approached, mentions: "I visit different parts of Paris, touristy and less so, treading in plenty of dog-poop, literal and metaphorical." The actual issue of dog mess in the streets of Paris (less prominent now than it used to be at the time when the book was first published, but still...) retrospectively makes the title stand out through the truth value of its denotation. As for its connotational value - the book is meant to stir interest through verbal indecorousness, presenting the Gallic fashion of doing things not so much in its savoir-être and savoir-faire dimensions, but more in a juicy way.

Actually, this novel is the one which started an entire collection of novels known as the "Merde series", which so far has reached its sixth stage: Merde Actually (2006), Merde Happens (2008), Dial M for Merde (2009), The Merde Factor (2013), Merde in Europe (2016). The interlinguistic metaphor in the title actuates a provocative parallel between the two cultures whose clash will make the backbone of the narrative. The title alludes to outlooks on life in a different culture hinted to be more often than not critical rather than understanding and favourable to the host country. In this interpretation of the title as an expressive illocutionary speech act, it casts the narrator producing it in the position of the victim of a cultural clash. Yet, without overlooking the inherent attachment to aspects viewed as superior in the host culture, it is fair to say that, while victimizing himself all throughout nine chapters, the narrator incessantly enjoys taking his revenge on the people he interacts with, by means of mordacious remarks and comments about the bizarreness of their idiosyncrasies.

The occurrence of the merde word in the title is also indicative of the narrator's penchant for risqué language in analysing the cross-cultural situations. The presence of a French word, in particular, also serves as an early indication of the presence of numerous French words and phrases sprinkled all throughout the novel. Their weight in the economy of the text comes from their use as cultural credentials, inherently implying the cross-cultural authority of the narrator as a (more or less) fluent speaker of the mother tongue of the foreign place he decided to settle in. As a result, they provide the local colour, functioning as a constant reminder of the foreign culture the plot is set in.

\section{The Culture Clash/Encounter Prefigured by the Editorial Peritext}

The first element of the editorial peritext, the cover of the novel, speaks volumes (pun intended) about the tonality of the content that is to follow. Both in the Bantam edition (2004) and the Black Swan edition (2005) the title is lettered in such a way as to draw attention on the French word. The shift in language and the foretaste of the contrastive examination of the two cultures is made apparent by the colours sported by the French noun, which are those of the French flag: the culture-loaded trilogy bleu, blanc, rouge. What stronger identity marker with regard to a nation than the flag of its country? The association between the signified of the linguistic sign and the symbol entailed by the visual occurrence of its signifier leads to a scathing summing up of an almost one year-long French experience, as if contending that Frenchness (or the French je ne sais quoi) amounted to nothing but merde. Hence the 
galling tonality of the account, for the storyteller, Paul West, is "the least politically correct man on the planet", as characterised by Clarke in the latest book of his Merde series. The peritext of the front cover, peritext taken in the widened acceptation of the genettian sense - including not only the preliminary text on the front cover but also the preliminary images, displays continuity in terms of the referral to the symbols carried by the ensign, as the French flag features also on the shell of a (culture-loaded) snail.

As for the ensemble created by the images chosen to advertise the novel on its front cover, roughly speaking, it consists of a representation of the Eiffel Tower (la Tour Eiffel, for the connoisseurs) and two snails, their shells wrapped in the British and French flags - all of the above featured against a plain white background. While culturally loaded, these images remain banal clichés for the French identity as seen by the Anglophones (the snail - metonymy for the French people derisively reduced to being snail and frog-eaters), or as recognized at a worldwide scale (la Tour Eiffel, the banner). However, the very choice of these overused images entails a specific perception of a French experience, one viewed as lacking extraordinariness and panache (that the popular belief would expect from such a place?).

The intriguing question is then: Will the content of the novel, alias the span of the cross-cultural experiences, actually surpass the threshold of this implied outright banality?

The iconographic ensemble can be broken down into three interconnected tiers. The effect created by the selection of worn-out, albeit representative images, is reinforced by the symbolism carried by their positioning against the simple white background. The Eiffel Tower is not only reclining (intimation of decline), but on top of it there is a French snail on whose top triumphantly stands an English one. The symmetry in the way the contrasting identities of the two snails are disclosed (the colours of the countries in question) is illustrative of the constant parallelism that will punctuate the account to come. If Frenchness has rubbed off on Britishness which, in its turn, has come to be represented by a snail, the Gallic snail is nevertheless ridden by its counterpart. The compromisingly submissive position of the former (could it be the "surrender" stereotype attached to Frenchness since World War II?) is a sample of the bawdy humour underlying the entire book, soon to be echoed in the first chapter presenting the circumstances that prompted the Englishman's settling down in Paris:

My good friend Chris told me not to come to France. Great lifestyle, he said, great food, and totally unpolitically correct women with great underwear. But, he warned me, the French are hell to live with. [...] Don't go there. Sorry, I told him, I've got to go and check out that underwear. (Clarke, 2005: 12)

The shallowness of the (seemingly) one and only reason proclaimed by the main character for wanting to forsake his native country of residence and settle down abroad prefigures the sardonic irony that is to underlie the narrative to come. While deriding its own enunciator, the overemphasised frivolity of the cause triggering the expatriation intently belittles whatever serious attraction the destination country, France, may hold on the foreigners' realm of imagination.

Last but not least, the background against which the symbols are staged is meant at pointing laughingly at another element peculiar to Frenchness, book covers. Two years into the publication of $A$ Year in the Merde, Clarke would ridicule the French bland choice of cover in his non-fiction book Talk to the Snail. Ten Commandments for Understanding the French:

French literary books have the most boring covers since Moses carved the commandments on to bar stone. Even then, Moses probably chose a nice shade of grey rock for his tablets. To be taken seriously, a littéraire novel must have a plain white cover with no decoration except for the title and the author's name in tiny lettering. Pale yellow is just about permissible so long as it is a joyless hue, the dull shade of the wallpaper in a run-down old people's home. Anything more flamboyant would devalue the words inside, which are of such profound import that it is almost sacrilege to print them on such a lowly, opaque substance as paper. They should be etched on glass so that the reader can see them in all their blinding clarity. (Clarke, 2006: 129)

The chapter addressing this characteristic of the French editorial peritext is inspiredly entitled "You Can Judge a Livre by Its Couverture". By mordantly distorting the English phrase "Don't judge a book by its cover" (which warns against deceptive appearances) and establishing a direct connection 
between the degree of monotony of the cover and the literary value of the book, this commentary is meant to expose the pretentiousness of the French custom of deliberately choosing to highlight the content of a book, by means of dismissing any soupçon of attractiveness that could possibly be displayed by its cover, as if text and editorial peritext were incompatible.

The semiotics of the back cover of the novel under discussion prolongs the humour and irony alluded to by the former one. It adverts the Eiffel Tower, in the same oblique position, but with even more harm done to it, for it is no longer erect and aiming for the sky, but appears to be curving, as if looked at through distorting glass. Does its position simply imply that the French values are more and more declining? Or could it hint, given the unavoidable human subjectivity, at a certain degree of distortion of truth, inherent to the attempt at summing up the essence of a nation in clear-cut statements, thus warning the reader to take the presentation that he is to read with a grain of salt?

The two snails - each with its shell wrapped in the flag of the country it stands for -, reappear, but this time in a confrontational pose, which defines the pervasive frenemy atmosphere of the account enclosed between the two covers.

Another similarity between the front and back cover is the resort to epitext, for they both boast a laudatory excerpt culled from a tabloid as a testimonial. In the Black Swan edition, the fragment gleaned from the mass market tabloid the Mirror: "Must-have comedy-of-errors diary about being a Brit abroad", revealing the type of narrative used in depicting a cultural contrast, is mirrored by an extract from the middle market tabloid the Daily Mail that contends the overwhelming popularity of this novel: "This is the season's word-of-mouth must-have book".

The construction of the blurb featuring on the back cover is two-tiered, moving from indirect free discourse to third person presentation. The introductory sentence, claimed by the editorial peritext and standing out visually since being typed in red, pertains to the narrative genre and prefigures the essence of the book as a quintessential journey of discovery of what is well and ill-founded respectively in the image of the other people: "Paul West arrives in Paris to start a new job - and finds out what the French are really like." This incipit is indirectly a commissive speech act, delivering the bold promise of making an accurate portrayal of the neighbouring people: "are really like". The foretaste, embracing the form of indirect free discourse, consists in the enumeration of a series of rather offensive stereotypes shown by the British with regard to the French, which are said to have been either validated or invalidated by the main character's experience. The endeavour to separate the fact from fiction in these cognitive shortcuts that are the hackneyed phrases implies the rendition of all the steps taken by the narrator while exerting his metacognitive cultural intelligence that led to his questioning his own cultural assumptions.

The array of observations that ensue, with their prevalent epistemic value, is thus polyphonic, encompassing both that voice of the English people that states what becomes the dictum of this paratext (consisting in widely-held and oversimplified ideas), and the voice of the main character's newly-lived experience that either confirms or invalidates the dictum:

They do eat a lot of cheese, some of which smells like pigs' droppings. They don't wash their armpits with garlic soap. Going on strike is the second national participation sport after pétanque. And, yes, they do use suppositories. (Clarke, 2005)

The polyphony transpires from the presence of both the validating and contrastive emphasis rendered through the auxiliary "do" and the interjection "yes" hinting at and responding to previously formulated opinions. As all the four stereotypes are originally negative ones, regardless of the conclusion drawn as a result of the protagonist's personal experience, their very quotation is emblematic of the relationship between the two peoples revealed here. The anodyne statement "They do eat a lot of cheese" is modified by the immediate rude comment comparing the smell of the cheese to the odour of pig faeces. The negation of a misconception, the would-be French habit of "washing their armpits with garlic soap", which is obviously an exaggeration triggered by another cultural representation, a prevailing ingredient of the French cuisine, also present in the traditional snail recipes, actually takes the form of a praeteritio, making the assertion of the questioned and questionable stereotype that strains credulity more powerful than its lack of consistency verified in the field. The nature of derided peculiarities making up the portrait of the otherness is as follows: two olfactory traits (a people redolent of foul-smelling cheese and garlic - "pig droppings", "garlic soap"), and three behavioural ones (always 
complaining, displaying lack of efficiency if not downright laziness since, in favourite French pastimes, going on strike is said to rank next to playing pétanque - an originally Provençal sport, with all the dolce farniente commonly linked to the sunny southern province -, and finally resorting to ludicrous medication). Deprived of its solemn status of a large-scale concerted protest destined to attain social justice au pays des droits de l'homme et du citoyen, organized by a body of employees against what they feel as oppressiveness, the French strike is relegated from the position of social regulator to that of a mere leisure activity; moreover, this cessation of work will be perceived by the body of foreigners as a rather annoying intrusion into their newly-broken daily routine.

The rest of the peritextual presentation, of editorial strain, focuses on: the general tone of the narrative ("laugh-out-loud account"), the summing up of the overall experience which comprises positive and negative aspects, and the usefulness of this novel to its readership in its dimension of survival guide abroad, providing good tips on the do's and don'ts in areas such as: tasting the local cuisine, managing relationships and housing projects:

In his first novel, Stephen Clarke gives a laugh-out-loud account of the pleasures and perils of being a Brit in France. A Year in the Merde tells you how to get served by the grumpiest Parisian waiter, how to make amour - not war and how not to buy a house in the French countryside.

Based on alliteration ("pleasures and perils"), the pair of contrastive French loans and true cognates (plaisirs et périls) meant to summarize in English the living abroad ensures the continuity of the back and forth movement between the English and the French ways of doing things, showing their interconnectedness and fascination with each other. The French insertion "amour" in "how to make amour - not war" is actually a reminder of the phrase that epitomised the 1960s in the US, "make love not war", with its reference to the free love promoted by the youth opposed to war and to the holders of traditional capitalist values, amongst which, marriage. The insertion of this French word, in particular, takes on a toponymic value and revives the romantic (or ribald?) connotations the city of Paris is reputed for.

Modalities of Rendition of the Culture Clash/Encounter Prefigured by the Paratext in the French Translation

The examination of the paratextuality of the French translation of this novel, done by Léon Mercadet, reveals the same discourtesy in portraying the relationships between the two cultures that makes the object of the book. There are cases when the disparaging elements in the source language are preserved in the target language, as they have French counterparts, and cases when the French wording discards certain offensive values borne by the English version, only to take on new ones, in the same facetious register.

In terms of construction techniques, the French title mirrors the English one, boasting a linguistic interaction between the two languages: God Save La France. As a matter of fact, the title of the French translation is entirely reliant on the English language and culture, in its intertextuality, in both its hypertext and hypotext, alluding to the national anthem of the United Kingdom, God Save the Queen. The scatological reference in French from the original version is no longer preserved, the French insertion highlighting the name of the country of adoption, this time. It remains true though, that at a crisscross analysis, the pair of French counterparts in the two versions of the title is pejorative and defamatory: merde - la France. In parallel fashion, but this time on a positive note, the shift from hypertext to hypotext unveils the pair la France - the Queen.

The deep structure of the title is the patriotic hymn of Great Britain, whose first verse reads: "God save our gracious Queen/ Long live our noble Queen/ God save the Queen./ Send her victorious/ Happy and glorious/ Long to reign over us:/ God save the Queen." The speech act entailed by the title of the anthem, in connection to its verses, is that of a wish or a plea. In ironic counterpoint, in the hypertext under discussion it becomes a wish addressed to divinity as a last resort, God being the only one who can still bring light upon this country. And since the prayer is uttered in English, could it mean that the salvation could only come from the other side of the Channel?

The French version of the book preserves the parallelism implied by the contrasting flags in the English original, as well as the use of clichés attached to the two nations and the allusion to their 
unrelenting contention for superiority. The graphic design of the front cover shows a horizontally halfcut silhouette of a lean gentleman dressed in a suit, treading the French flag and carrying a big umbrella with the British flag.

The blubs on the back cover of the source and target language complement each other, each contributing to the overall moral of the story. They are both in keeping with the spirit of composition of the matching English and French idioms referring to the shameful act of taking "a leave of absence without announcing one's departure", namely: "to take a French leave" and its reversed pendant "filer à l'anglaise". Thus, at first sight, the main target of ridicule of the English blurb consists in the French customs; vice versa, the French focus of blurb derisiveness is the British protagonist of the story. The point made, actually, is that there are no such things as universal "right" and "wrong" labels to be doomfully and immutably attached to a particular nationality.

The promotional notice on the back cover of the translation unfolds in two stages. First, it takes the form of an excerpt from a peculiar double-edged Curriculum Vitae of the main character, Paul West. The order of the CV headings starts by following a standard CV template, conveying personal details such as name and age, only to immediately divert from the typical structure and become highly subjective, both in the order of the headings and in the information supplied. Right after the personal details, the next heading reads Langue française, given the importance of mastering the language of the country of residence and also the well-known attachment of the French to their language, the disclosed information being slyly disparaging in terms of the respect that should be shown to the language of the host country: "niveau très moyen". The Position heading mockingly shows Paul West as a proactive individual, in a high place in the company where he works, particularly committed to his professional duties and with brilliant career prospects: "jeune cadre dynamique promis à un grand avenir". And yet, in spite of all these attributes advertising a fulfilled existence, the young man's ultimate day-to-day pursuit is to constantly be on the lookout so as to thwart the efforts of the insidious French daily life to take a toll on life as he knows it as a Brit. In further irony, West's résumé segues into the Hobby section (ou pardon, Hobbie), that contains a racy one - women's lingerie, which, as seen in the examination of the version originale of the novel, will be maintained in the first chapter as the compelling reason for having left England for France (see supra):

- Mon ami Chris m'avait prévenu : «Ne va pas en France. Là-bas la vie est classe : bouffe classe, femmes politiquement très incorrectes, sous-vêtements classe. L'ennui, c'est que les Français sont impossibles à vivre. » [...]

- Excuse-moi, avais-je répondu, mais je dois tirer au clair cette affaire de sous-vêtements. (Clarke, 2005: 9-10)

The last section of this untypical CV refers to the character's prevailing individuality trait, which consists in what may be seen as an ideal crossbreed between two well-exported British celebrities, an actor and a footballer. Paul West's distinguishable trademark reads: "Paul West serait le fruit du croisement génétique entre Hugh Grant and David Beckham.”

The latter part of this blurb is a synthetic presentation of the hero and the adventures he embarks on in the foreign land: "Jeune Britannique fraîchement débarqué à Paris, créateur, en Angleterre, de la fameuse enseigne Voulez-Vous Café Avec Moi, Paul a bien du mal à s'adapter au pays des suppositoires, des grèves improvisées et des déjections canines. ". It thus implies the constant parallelism between two culturally-determined ways of seeing life: "jeune Britannique/ Paris", the continuous process of adaptation and adjustment to a new culture the hero is going through: "Paul a bien du mal à s'adapter au pays", the malicious clichéd images which lump an entire people into presumptuously welldelineated categories: "pays des suppositoires, des grèves improvisées et des déjections canines". The finishing line of the description, «Et il n'est pas au bout de ses surprises... », accomplishes a commissive speech act, promising, by means of the naturally expected knowledge accretion, to unlock stunning secrets of what it takes to live life as a Frenchman.

For right after the skewering of Frenchness accomplished by the cover design of the novel, there comes the next logical question, with regards to its content, and subsequently to the degree of intercultural competence that will be displayed by the characters: Is there anything at all that may be appreciated at the Other? 
The extent to which the answer to this question raised by the paratext is "Yes, there is." remains to be grasped after the reading of the text itself.

\section{Conclusion}

To put it in a nutshell, the paratext of this relocation narrative, both in its original English version and in its translation into French is illustrative of the French or Foe? formula which in 1994 became the title of a renowned American book on Frenchness, written by Polly Platt. From the worded messages to the images featuring on the book covers, that is, from the entire humorous and incisive layout of the graphic design, the elements surrounding the main body of the novel intimate a love-andhate relationship between two abutting countries. In this rivalry in which they are both relentlessly vying for supremacy, the English side appears to have managed to gain the upper hand (or at least, for now), as the British snail and lean gentleman give us to understand. Viewed as frenemies, the two cultures appear yet unable to avoid staying in touch, the description of their encounter and clash in this novel being characterized by a constant briskly-paced comedic repartee.

For this book is about more than sheer self-importance, and beyond this or that reproof of local aspects, the butt of ridicule is anyone who takes themselves too seriously, missing the essential moral of their cross-cultural experiences, whatever nationality they may be.

\section{WORKS CITED}

Ang, S., Van Dyne, L. 2008. "Conceptualization of cultural intelligence: Definition, distinctiveness, and nomological network." In: Ang, S. and Van Dyne, L., (eds.), Handbook of Cultural Intelligence: Theory, measurement and applications, 3-15, New York, NY: M. E. Sharpe, 3-15.

Ang, S., Van Dyne, L., Koh, C. 2006. "Personnality correlates of the four-factor model of cultural intelligence." Group \& Organization Management 31. 100-123.

Clarke, S. 2005. A Year in the Merde. London: Black Swan (First published in 2004 by Bantam Press).

Clarke, S. 2005, God Save La France. Transl. into French by Léon Mercadet. Paris: NiL editions.

Clarke, S., 2006, Talk to the Snail. Ten Commandments for Understanding the French, London: Bantam Press.

Clarke, S., 2011. "Author Interview with Stephen Clarke." Reading Is Fashionable. Online address: http://readingisfashionable.com/2011/04/author-interview-with-stephen-clarke.html. Retrieved on $24^{\text {th }}$ of May 2016.

Earley, P. C., Ang, S. 2003. Cultural intelligence: individual interactions across cultures. Palo Alto, CA: Stanford University Press.

Genette, G. 1982. Palimpsestes: La Littérature au second degré. (Palimpsests: Literature in the second degree.), Paris: Seuil.

Knox, E. C. 2003. "A literature of accommodation." French Politics, Culture and Society vol. 21, no. 2. Special Issue: Déjà Views: How Americans Look at France. 95-110.

George, D., Sattin, A. (eds.) 2002. A House Somewhere: Tales from Life Abroad. London: Lonely Planet Publications.

Mastellotto, L. A. 2013. Relocation Narratives "Made in Italy" Self and Place in Late-Twentieth Century Travel Writing. $\mathrm{PhD}$ Thesis, University of East Anglia, Online address: https://ueaeprints.uea.ac.uk/48809/1/2013MastellottoLAPhD.pdf. Retrieved on 20 $0^{\text {th }}$ of May 2016.

Ross, S. 2009. "Home and away: Tuscan abodes and Italian Others in contemporary travel writing", Studies in Travel Writing, vol.13, issue 1. 45-60.

Ross, S. 2010. Tuscan Spaces: Literary Constructions of Place. Toronto, University of Toronto Press.

Searle, J. R. 1975. "A taxonomy of illocutionary acts." Language, Mind and Knowledge. Minnesota Studies in the Philosophy of Science, vol. 9, 344-369.

Sternberg, R. J. 1986. "A framework for understanding conceptions of intelligence” In: Sternberg R. J. and Detterman, D. K. (eds.), What is Intelligence?, Norwood, N. J.: Ablex, 3-18. 